\title{
Evaluation of the CropSyst model for simulating the potential yield of cotton
}

\author{
Rolf SOMMER $^{1 *}$, Kirsten KIENZLER ${ }^{1}$, Christopher CONRAD $^{2}$, Nazar IBRAGIMOV $^{3}$, John LAMERS $^{1}$, \\ Christopher MARTIUS ${ }^{1}$, Paul VLEK ${ }^{1}$

\footnotetext{
${ }^{1}$ ZEF, Center for Development Research, Department of Ecology and Resource Management, University of Bonn, Walter-Flex-Str. 3, 53113 Bonn, Germany

${ }^{2}$ Remote Sensing Unit, Department of Geography, University of Würzburg, Am Hubland, 97074 Würzburg, Germany

${ }^{3}$ Uzbek Cotton Research Institute, Tashkent, Uzbekistan
}

(Accepted 14 January 2008)

\begin{abstract}
Cotton produced in Uzbekistan has a low water and fertilizer use efficiency and yield is below its potential. To introduce improved production methods, knowledge is required on how the agro-ecosystem would respond to these alternatives. For this assessment, dynamic simulation models such as the crop-soil simulation model CropSyst are useful tools. CropSyst had never been applied to cotton, so it first was calibrated to the cotton variety Khorezm-127 grown under researcher-managed optimal conditions in the Khorezm region of Uzbekistan in 2005. The model performance was evaluated with a data set obtained in 2004 on two farmer-managed sites. Both data sets comprised insitu measurements of leaf area index and aboveground biomass. In addition, the 2004 data set included the normalized difference vegetation index derived from satellite imagery of the two cotton fields, which provided estimations of leaf area index with a high temporal resolution. The calibrated optimum mean daily temperature for cotton growth was $25{ }^{\circ} \mathrm{C}$, the specific leaf area $13.0 \mathrm{~m}^{2} \mathrm{~kg}^{-1}$, the leaf/stem partition coefficient 3.0, the biomass/transpiration coefficient $8.1 \mathrm{~kg} \mathrm{~m}^{-2} \mathrm{kPa} \mathrm{m}^{-1}$ and the radiation use efficiency $2.0 \mathrm{~g} \mathrm{MJ}^{-1}$. Simulations matched 2005 data, achieving a root mean square error between simulated and observed leaf area index and aboveground biomass of $0.36 \mathrm{~m}^{2} \mathrm{~m}^{-2}$ and $0.97 \mathrm{Mg} \mathrm{ha}^{-1}$, respectively. The evaluation showed that early cotton growth and leaf area index development could be simulated with sufficient accuracy using CropSyst. However, final aboveground biomass was slightly overestimated by CropSyst, because some unaccounted plant stress at the sites diminished actual aboveground biomass, leading to a root means square error of around $2 \mathrm{Mg} \mathrm{ha}^{-1}$. Some characteristics of cotton, such as the indeterminate growth habit, could not be incorporated in detail in the model. However, these simplifications were compensated by various other advantages of CropSyst, such as the option to simulate crop-rotation or its generic crop growth routine that allows modelling of additional, undocumented crops. The availability of normalized difference vegetation index data with a high temporal and acceptable spatial resolution opened possibilities for a precise, in-expensive and resource-efficient way of model evaluation.
\end{abstract}

crop modelling / decision support system / NDVI / leaf area index / plant stress / Khorezm

\section{INTRODUCTION}

Uzbekistan is the world's second largest exporter of cotton (Gossypium hirsutum L.) lint with 0.45 Million tons in 2004 according to FAOSTAT (2006) following the United States with 2.9 Million tons. Countrywide per hectare rawcotton productivity in 2005 was estimated at $2.7 \mathrm{Mg}$ (FAOSTAT, 2006). This was higher than the world average of $1.9 \mathrm{Mg} \mathrm{ha}^{-1}$ but less than the $4.2 \mathrm{Mg} \mathrm{ha}^{-1}$ achieved under similar climatic conditions in Australia. About $5 \%$ of the cotton in Uzbekistan is produced in Khorezm, one of the twelve

* Corresponding author: r.sommer@ cgiar.org

Current address: International Center for Agricultural Research in the Dry Areas (ICARDA), PO Box 5466, Aleppo, Syrian Arab Republic. regions of Uzbekistan located in the northwestern part of the country, about $270 \mathrm{~km}$ south of the present shores of the Aral Sea, and surrounded by deserts. Crop production is feasible with irrigation only, but with regard to the moderate yields, irrigation water use is disproportionally high. Official recommendations by the Central Asian Scientific Irrigation Research Institute (SANIIRI) range from $500-800 \mathrm{~mm}$ per year, excluding the annual pre-season salt leaching requirements of around $100-400 \mathrm{~mm}$. However, recent studies showed that sometimes as much as $1700 \mathrm{~mm} \mathrm{a}^{-1}$ was applied for cotton production (Conrad, 2006).

According to national established recommendations, cotton grown on irrigated alluvial meadow soils (calcaric gleyic Arenosols according to FAO soil classification), the dominating soil in the study region, should receive about 


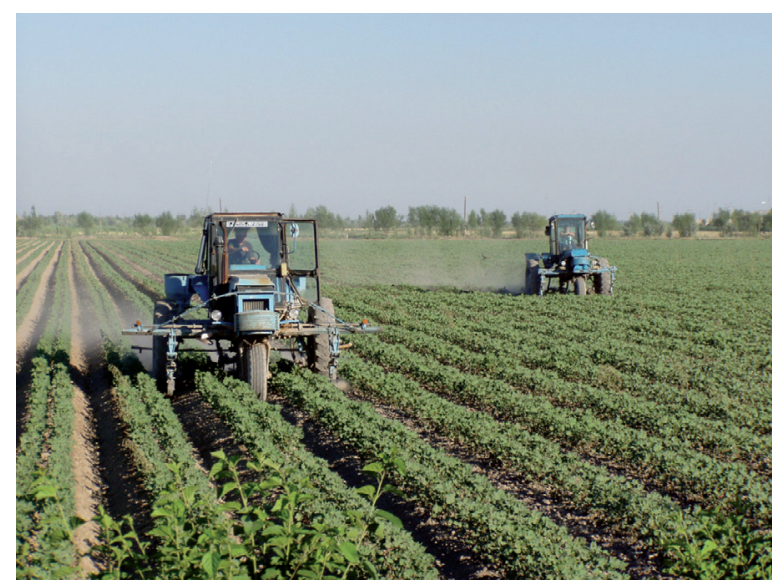

Photo 1. Fertilization and reshaping of furrows for irrigation of cotton in Khorezm, Uzbekistan; (c) Conrad, 2004.

200-250 $\mathrm{kg} \mathrm{N} \mathrm{ha}^{-1}$ to produce $2.5-3.5 \mathrm{Mg} \mathrm{ha}^{-1}$ of raw cotton. $\mathrm{N}$-fertilizer is applied mostly as ammonium-nitrate and urea (Photo 1). At these rates, these fertilizers pose a risk of $\mathrm{N}$ pollution to the shallow groundwater, and in combination with the high irrigation water applications showed large gaseous losses (Scheer et al., 2008).

Soil salinization is another constant threat to agricultural production in Khorezm and Uzbekistan. The irrigation system shows considerable conveyance losses, which in combination with ill-functioning drainage systems causes the groundwater table in Khorezm to rise often above critical levels. The consequence is secondary soil salinization. In 2004, about $45 \%$ of the soils in Khorezm were classified as medium to highly saline (Ismoilov, 2004).

The introduction of resource-conserving production methods will require insights on how such alternatives will affect present agricultural productivity and production economics. However, studying the integrated effects of management, environment and eco-physiological characteristics in a predictive fashion would require complicated field experiments. Quantitative, system-dynamic tools such as crop-soil simulation models can complement single and multi-factor research by assessing the integrated impact of variables on productivity and resource conservation. The crop-soil simulation model CropSyst can serve such purposes.

CropSyst has been applied to a range of crops (e.g. Pannkuk et al., 1998; Confalonieri and Bechini, 2004; Confalonieri and Bocchi, 2005; Bechini et al., 2006; Confalonieri et al., 2006; Sommer et al., 2007). It has a generic routine to simulate the growth of annual, herbaceous plants and this routine can be adapted to any new crop meeting this criterion. Algorithms for some biological processes are simplified compared to other crop-soil simulation models. Thus, with regard to crop parameters CropSyst is appreciated for its "small appetite for data" (Confalonieri and Bechini, 2004). CropSyst had not been used for simulating cotton growth as cotton is not a herbaceous, annual plant, though nowadays it is cultivated as such. Also, the photosynthesis of cotton varies with plant age (Peng and

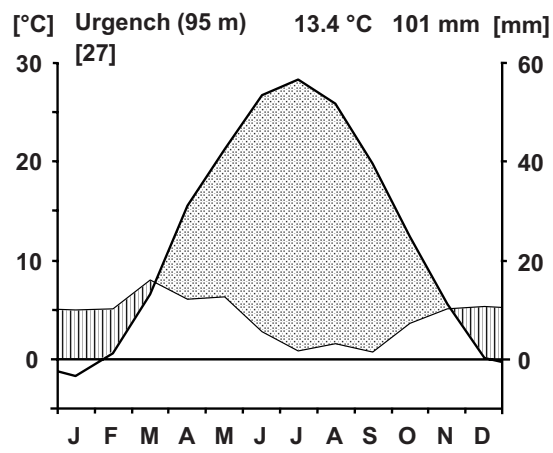

Figure 1. 1980-2006 monthly mean air temperature and monthly precipitation in Khorezm (diagram according to Walter-Lieth notation).

Krieg, 1991), and the 1:1 applicability of the classical concept of growing degree days to cotton has been repeatedly questioned (Constable, 1976; Bradow and Davidonis, 2000; Bange and Milroy, 2004). These peculiarities of cotton pose some additional challenges to the generic crop growth routine of CropSyst.

The aim of the German-Uzbek International Research Project on 'Economic and Ecological Restructuring of Land and Water Use in the Region Khorezm' is to develop a decision support system for a spatially explicit optimization of cropping patterns and rotations for regional decision-makers (http://www.khorezm.uni-bonn.de/). This paper describes the application of CropSyst for the simulation of optimal cotton growth in Khorezm, which is a first step in developing such decision support system. Before it can be applied, CropSyst must be upgraded to simulate the effects of water-, salt- and $\mathrm{N}$-stress, which are key to the yield constraints for cotton in Khorezm (Martius et al., 2004). The Normalized Difference Vegetation Index (NDVI) was used to derive leaf area index data with a high temporal resolution as a substitute for labourintensive and destructive in-situ leaf area index determination. Data originated from $250 \mathrm{~m}$ resolution MODIS satellite imagery.

\section{MATERIALS AND METHODS}

\subsection{Location}

Experimental data were collected in the Khorezm region located in northwestern Uzbekistan, on the left bank of the Amu Darya River within the transition zone of the Karakum and Kyzylkum deserts. This region is characterized by a semidesert climate. Potential evapotranspiration exceeds precipitation during most of the year and hot and dry summers alter with cold winters. The region receives around $100 \mathrm{~mm}$ precipitation from October to May (Fig. 1), but neither summer nor winter precipitation plays a significant role in the water balance of the region. Crop production of mostly cotton, wheat, and rice fully relies on irrigation water that is withdrawn from the Amu Darya. 


\subsection{Experimental data}

Experimental data for model calibration were collected in 2005 in Urgench district, Khorezm, on a researchermanaged fertilizer-response trial that was laid out in factorial block design with four replications and located $41^{\circ} 60 ' 25^{\prime} \mathrm{N}$, 6051'47'E (for more details see Kienzler's Ph.D. dissertation). The common cotton variety Khorezm-127 was planted 2 May on plots of $4.8 \mathrm{~m} \times 10 \mathrm{~m}$ with a density of 8 plants $\mathrm{m}^{-2}$, i.e. with a spacing of $0.6 \mathrm{~m} \times 0.2 \mathrm{~m}$. Khorezm- 127 has a vegetation period of 125-135 days, reaches a maximum height of $120 \mathrm{~cm}$ and is tolerant against cotton wilt. The experiment comprised different amounts of $\mathrm{N}$ fertilizer as well as various forms and combinations of $\mathrm{N}$-fertilizer and different application dates. For model calibration only the data were selected from treatments with $\mathrm{N}$ fertilization equal or above $160 \mathrm{~kg} \mathrm{~N} \mathrm{ha}^{-1}(\mathrm{n}=6)$ and with recommended rates of $\mathrm{P}$ and $\mathrm{K}$ fertilizer to ensure that nutrient constraints did not occur. Aboveground biomass and green ${ }^{1}$ leaf area were determined five times during the cropping period. Each time six plants per plot where randomly selected and harvested and the leaf area determined with a leaf area meter (Li-Cor, LI-3100). Additionally, 8-20 plants were harvested on each plot for biomass determination. Biomass was separated into leaves, stems, flowers and bolls, if applicable. Leaf areas $\left(\mathrm{m}^{2}\right)$ were converted into leaf area index $\left(\mathrm{m}^{2} \mathrm{~m}^{-2}\right)$ based on the plant density of 8 plants $\mathrm{m}^{-2}$. Similarly, aboveground biomass was expressed on an area-basis. During the growing season of 2004, leaf area index and corresponding biomass of Khorezm-127 was repeatedly measured on two farmer's fields located in different districts of Khorezm (Blenk, 2005, Photo 1).

The first field was located in Khiva $\left(41^{\circ} 22^{\prime} 42^{\prime \prime} \mathrm{N}\right.$, $\left.60^{\circ} 16^{\prime} 40^{\prime \prime} \mathrm{E}\right)$, and the second field in Khonka $\left(41^{\circ} 30^{\prime} 30^{\prime} \mathrm{N}\right.$, $\left.60^{\circ} 50^{\prime} 29^{\prime} \mathrm{E}\right)$. Both fields were planted at the same density as outlined above. On the Khonka field cotton was planted around 25 April. The field in Khiva was planted on 5 April, but due to poor emergence it was replanted on 8 May. Farmers confirmed that each field was fertilized according to Uzbek recommendations for cotton and irrigated at least four times during the growing season. Blenk (2005) noted that cotton development on the two fields was fast and homogenous.

In each field the leaf area index of one bulk sample of all leaves collected from 13 randomly distributed $1 \mathrm{~m}^{2}$-subplots was repeatedly measured using the Li-Cor LI-3100 leaf area meter. Before destructive sampling, the leaf area index of the subplots was estimated with a plant canopy analyzer (Li-Cor, LAI-2000). A regression analysis of leaf area index (LAI) determined with the leaf area meter and the leaf area index estimated with the LiCor LAI-2000 yielded LAI_observed = $0.872 \times$ LAI_LiCor +0.056 . The regression coefficient was 0.925 and the standard error of estimate $0.174 \mathrm{~m}^{2} \mathrm{~m}^{-2}(\mathrm{n}=$ 12). Consequently, non-destructive observations of leaf area index were conducted using the LAI-2000 device between and beyond the times of destructive sampling, for each field at least

\footnotetext{
${ }^{1}$ In all our studies always the green leaf area or green leaf area index was determined. For simplification, this will henceforth be addressed as leaf area (index).
}

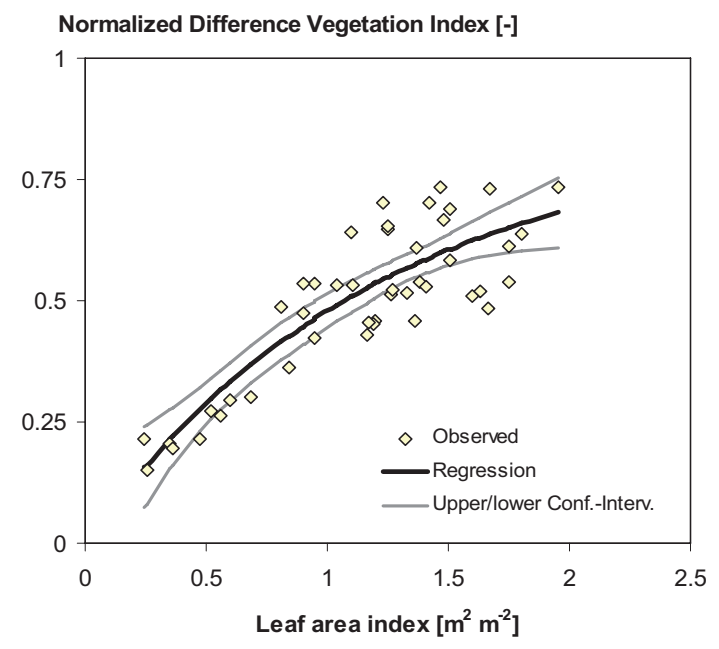

Figure 2. Non-linear regression of the Normalized Difference Vegetation Index (NDVI) derived from MODIS-satellite reflectance data and field-observed Leaf area index (LAI); grey lines: upper and lower $95 \%$ confidence interval; the regression equation is NDVI $=0.851-$ $0.851 \mathrm{e}^{-0.828 L A I}$ with a $\mathrm{R}^{2}$ of 0.762 and a standard error of the estimate of $0.079(n=44)$.

six times during the cropping season with 55 to 86 replicates per field.

We used the 2004 data set on leaf area index, i.e. destructive sampling and LAI-2000-derived, and biomass development of these two fields to evaluate the calibrated CropSyst cotton model. We assumed that plant development was optimal or close-to-optimal, as fertilization and irrigation was carried out according to official recommendations (Blenk, 2005).

In a second step, the remote sensing based Normalized Difference Vegetation Index (NDVI) of the same fields and same observation period were compared with the aforementioned leaf area index data. The NDVI is a measure of greenness density of the vegetation (Huete et al., 2002). It was derived from daily $250 \mathrm{~m}$ MODIS red (RED) and near infrared (NIR) reflectance data as follows:

$$
\mathrm{NDVI}=\frac{\mathrm{NIR}-\mathrm{RED}}{\mathrm{NIR}+\mathrm{RED}} .
$$

We used the concept introduced by Baret and Guyot (1991) to describe the relationship between NDVI and green leaf area index:

$$
\mathrm{NDVI}=\mathrm{NDVI}_{\mathrm{as}}+\left(\mathrm{NDVI}_{\mathrm{bs}}-\mathrm{NDVI}_{\mathrm{as}}\right) \times \mathrm{e}^{-\mathrm{k} \times \mathrm{LAI}}
$$

where $\mathrm{NDVI}_{\mathrm{as}}$ is the asymptotic value of NDVI when leaf area index tends towards infinity, $\mathrm{NDVI}_{\mathrm{bs}}$ is the NDVI of the bare soil, and $\mathrm{k}$ is the radiation extinction coefficient.

In a non-linear regression analysis, this equation was fitted to observed cotton leaf area index (LiCor LAI-2000) and corresponding NDVI data $(\mathrm{n}=44)$. This resulted in $\mathrm{NDVI}_{\mathrm{as}}=$ $0.851, \mathrm{NDVI}_{\mathrm{bs}}=0$ and $\mathrm{k}=0.828$ (Fig. 2).

We compared the CropSyst-simulated leaf area index with the NDVI-derived leaf area index using the re-arranged regression equation (2). The advantage of this type of 
comparison is the higher frequency of observations: 20 satellite images of 8-day MOD09 surface reflectance composites (Vermote et al., 2002) could be used as opposed to only eight field measurements of leaf area index. The integration over a larger area allows for a more representative assessment of leaf area index than with manual determination of leaf area index. However, estimates of leaf area index over larger areas by satellite imagery bears the risk of including neighbouring noncotton fields. This could not be fully excluded for the Khiva site, where Blenk (2005) determined that due to the small field size, $<25 \%$ of the satellite image pixel did not cover a single field. The Khonka field was larger so that one pixel fully covered the field and two additional, neighboured pixels had at least $50 \%$ coverage.

Meteorological data such as solar radiation, air temperature, humidity and wind speed were collected with an automatic weather station (WatchDog 900ET) next to the experimental site in Urgench district ( $\left.41^{\circ} 60^{\prime} 20^{\prime \prime} \mathrm{N}, 60^{\circ} 51^{\prime} 42^{\prime \prime} \mathrm{E}\right)$ from 2004 to 2006 . The 2004 and 2006 data set was used to simulate cotton growth in these years. Model performance was assessed based on variations and stability of yields across the different years.

\subsection{Model description and parameterization}

We used CropSyst version 4.09.05, which is a multi-crop, daily time step cropping system simulation model (Stockle et al., 2003). Crop development is considered as a function of accumulated growing degree days. Three equations govern the daily potential aboveground biomass accumulation. The daily potential transpiration-dependent biomass accumulation, $\mathrm{B}_{P T}$ $\left[\mathrm{kg} \mathrm{m}^{-2}\right.$ day $\left.^{-1}\right]$, is calculated by:

$$
\mathrm{B}_{\mathrm{PT}}=\frac{\mathrm{BTR} \times \mathrm{T}_{\mathrm{act}}}{\mathrm{D}}
$$

where BTR is the aboveground biomass-transpiration coefficient $\left[\mathrm{kg} \mathrm{m}^{-2} \mathrm{kPa} \mathrm{m}^{-1}\right], \mathrm{T}_{a c t}$ is the actual transpiration $\left[\mathrm{m} \mathrm{day}^{-1}\right]$, and $\mathrm{D}$ is the vapour pressure deficit $[\mathrm{kPa}]$.

The daily radiation-dependent growth, $\mathrm{B}_{\text {Rad }}\left[\mathrm{kg} \mathrm{m} \mathrm{m}^{-2}\right.$ day $\left.^{-1}\right]$, is calculated by:

$$
\mathrm{B}_{\mathrm{Rad}}=\mathrm{T}_{\lim } \times 0.001 \times \mathrm{RUE} \times \mathrm{PAR} \times\left(1-\mathrm{e}^{-\mathrm{k} \times \mathrm{LAI}}\right)
$$

where $\mathrm{T}_{\text {lim }}$ is an air temperature dependent, growth-limiting factor, linearly increasing from 0 at base temperature to 1 at optimum mean daily temperature for growth. RUE is the radiation use efficiency $\left[\mathrm{g} \mathrm{MJ}^{-1}\right]$. PAR is the photosynthetic active radiation approximated in the model by $0.5 \times$ solar radiation $\left[\mathrm{MJ} \mathrm{m}^{-2} \mathrm{day}^{-1}\right.$ ], and $\left(1-\mathrm{e}^{-\mathrm{kLAI}}\right)$ is the fraction of PAR intercepted by the canopy and where $\mathrm{k}$ is the radiation extinction coefficient.

The daily increase in leaf area index (LAI) is calculated as:

$$
\mathrm{LAI}=\frac{\mathrm{SLA} \times \mathrm{B}}{1+\mathrm{SLP} \times \mathrm{B}}
$$

where SLA is the specific leaf area $\left[\mathrm{m}^{2} \mathrm{~kg}^{-1}\right]$, i.e. the ratio of leaf area to leaf dry biomass, SLP is an empirical stem leaf partitioning coefficient $\left[\mathrm{m}^{2} \mathrm{~kg}^{-1}\right]$ and $\mathrm{B}$ is the accumulated aboveground biomass $\left[\mathrm{kg} \mathrm{m}^{-2}\right]$.

The calculation of daily potential evapotranspiration follows the crop coefficients approach analogous to Allen et al. (1998) and uses the Penman-Monteith method. In all simulations the N-routine, i.e. N-stress, and the salinity-routine were disabled. In addition, sufficient irrigation was introduced to exclude water stress. Thus, the influence of soil properties on plant growth was completely eliminated, as necessary for simulating cotton growth potential.

Since CropSyst had previously not been applied to simulate cotton growth, it did not include default plant-physiological and phenological parameters for cotton. Yet, CropSyst contains a generic crop growth routine to simulate growth of virtually any new crop once a standard set of parameters (Tab. III) is introduced. This specific data set allowed that cotton would have an annual life cycle and produce 'seeds' as a substitute for the raw cotton bolls, which is the harvested economic valuable product. Though these simplifications do not perfectly reflect real cotton growth with its 'indeterminate growth habit' (Peng and Krieg, 1991), they constituted a first practical compromise for gaining a management-oriented understanding for cropping system purposes while gaining important insights into crop-environment interactions.

Cotton plant phenology was derived from in-situ observations, with the exception of accumulated growing degree days from seeding to plant maturity. The latter was assumed to occur at the first cotton pick date. Initial green leaf area index was set to the model default value of $0.011 \mathrm{~m}^{2} \mathrm{~m}^{-2}$. The specific leaf area was determined by the ratio of leaf area to corresponding leaf biomass determined in-situ. The radiation extinction coefficient was set to 0.9 as observed by Ko et al. (2005), because we lacked field data for it. Base temperature, cut-off temperature, optimal mean daily temperature for growth, the biomass-transpiration coefficient, the radiation use efficiency and the leaf/stem partition coefficient derived from equation (3-5) were calibrated manually by fitting simulated leaf area index and aboveground biomass to observations made in 2005.

\subsection{Statistical evaluation}

Statistical evaluations of results comprised analyses of variance (ANOVA), regression analyses and the calculation of the root mean square error (RMSE) between observations and simulation results, which is:

$$
\text { RMSE }=\sqrt{\frac{\sum_{\mathrm{i}=0}^{\mathrm{n}}\left(\text { Observed }_{\mathrm{i}}-\text { Simulated }_{\mathrm{i}}\right)^{2}}{\mathrm{n}}}
$$

\section{RESULTS AND DISCUSSION}

\subsection{5 experimental results}

\subsubsection{Phenology}

Cotton was planted on 2 May 2005, which was slightly later than usual. Plants emerged ten days later $\left(110^{\circ} \mathrm{C}\right.$-days $)$. 
Table I. Development of aboveground biomass and leaf area index of cotton during the cropping season 2005; SD = standard deviation.

\begin{tabular}{cccccc}
\hline Date & $\begin{array}{c}\text { Days after } \\
\text { planting }\end{array}$ & \multicolumn{2}{c}{$\begin{array}{c}\text { Aboveground biomass } \\
{\left[\mathrm{Mg} \mathrm{ha}^{-1}\right]}\end{array}$} & \multicolumn{2}{c}{$\begin{array}{c}\text { Leaf area index } \\
{\left[\mathrm{m}^{2} \mathrm{~m}^{-2}\right]}\end{array}$} \\
& & Mean & SD & Mean & SD \\
\hline 7 June & 36 & 0.04 & 0.01 & 0.04 & 0.01 \\
24 June & 53 & 0.59 & 0.19 & 0.38 & 0.10 \\
11 July & 70 & 3.61 & 1.31 & 1.41 & 0.39 \\
6 August & 96 & 7.89 & 0.72 & 2.74 & 0.41 \\
14 September & 135 & 10.83 & 1.72 & 1.62 & 0.21 \\
\hline
\end{tabular}

Flowering started in mid-July. On 29 August around 50\% of the plants had 1-2 open bolls. The first, second and third cotton pick was done $13-14 / 9,4-5 / 10$ and $24-25 / 10$, on average contributing $49 \%, 35 \%$ and $16 \%$ to total yield, respectively. The remaining aboveground biomass was removed after the third pick. The woody stems of cotton are usually used as fuel.

\subsubsection{Yield, biomass leaf area index and specific leaf area}

Total raw cotton yield, i.e. cotton lint and seeds of the three picks, in 2005 on average ( \pm standard error) was $4.46 \pm$ $0.22 \mathrm{Mg} \mathrm{ha}^{-1}$. Yield was not significantly different between the six optimally fertilized treatments (one-way ANOVA, $P \leqslant 0.05$ ). Also, total aboveground biomass at first pick with $10.83 \pm 0.44 \mathrm{Mg} \mathrm{ha}^{-1}$ and a harvest index of $0.41 \pm 0.01 \mathrm{did}$ not differ significantly between the N-treatments. Aboveground biomass accumulation and leaf area index development were related linearly until leaf area index peaked at $2.74 \mathrm{~m}^{2} \mathrm{~m}^{-2}$ on 6 August, i.e. 96 days after planting (Tab. I).

Subsequently, aboveground biomass accrual slowed down, whereas leaf area index dropped to $1.62 \mathrm{~m}^{2} \mathrm{~m}^{-2}$ by 14 September. The maximum observed leaf area index was within previously reported ranges for cotton. E.g. Peng and Krieg (1991) reported maximum leaf area indices between 2.5 to $3 \mathrm{~m}^{2} \mathrm{~m}^{-2}$ for 101-days-old cotton (Paymaster 792) grown with different row densities in Texas. Also Milroy and Bange (2003) reported a maximum leaf area index of 2.84 for cotton (Sicala V-2i) grown in 1998 in northwestern South Wales, Australia, and fertilized with $120 \mathrm{~kg} \mathrm{~N} \mathrm{ha}^{-1}$. Ko et al. (2005) presented maximum leaf area indices for irrigated cotton (Paymaster 2326 $B G / R R$ ) grown in Texas that ranged between 2 and $5 \mathrm{~m}^{2} \mathrm{~m}^{-2}$ depending on the year of observation. Rosenthal and Gerik (1991) observed leaf area indices for the cotton variety Acala $S J-2$ grown in Texas of nearly $7 \mathrm{~m}^{2} \mathrm{~m}^{-2}$, for plant densities of 14 plant $\mathrm{m}^{-2}$, almost double the density used in this study. The specific leaf area of Khorezm-127 on average was $13.0 \mathrm{~m}^{2} \mathrm{~kg}^{-1}$ with higher than average initial values for young plants and lower values for the comparably thicker, sclerophytic leaves of mature plants (Fig. 3).

The average specific leaf area was slightly higher than the value of $10 \mathrm{~m}^{2} \mathrm{~kg}^{-1}$ reported by Ko et al. (2005) but lower than the 14 to $27 \mathrm{~m}^{2} \mathrm{~kg}^{-1}$ monitored by Reddy et al. (1989), highlighting genotypic and probably also environment-related differences in this parameter and underlining the need for determination of this parameter for specific conditions and varieties.

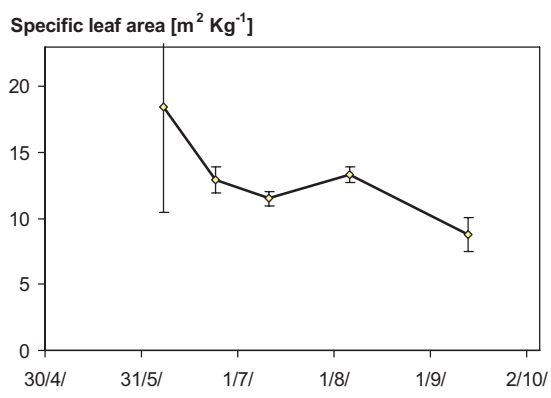

Figure 3. Specific leaf area of cotton during the vergetation season $2005 ; n=6$, bars denote the standard deviation.

Table II. Observed (Blenk, 2005) and simulated aboveground biomass of cotton in 2004.

\begin{tabular}{|c|c|c|c|}
\hline \multirow[t]{3}{*}{ Location } & \multirow[t]{3}{*}{ Date } & \multicolumn{2}{|c|}{ Aboveground biomass } \\
\hline & & Observed & Simulated \\
\hline & & \multicolumn{2}{|c|}{$\left[\mathrm{Mg} \mathrm{ha}^{-1}\right]$} \\
\hline \multirow[t]{3}{*}{ Khonka } & 21-Jul & 2.35 & 3.87 \\
\hline & 25-Aug & 7.07 & 8.83 \\
\hline & 29-Sep & 8.15 & 10.80 \\
\hline \multirow[t]{4}{*}{ Khiva } & 22-Jun & 0.64 & 0.30 \\
\hline & 20-Jul & 3.86 & 2.55 \\
\hline & 25-Aug & 8.68 & 7.53 \\
\hline & 28-Sep & 7.43 & 10.43 \\
\hline \multicolumn{4}{|c|}{ Root mean square error } \\
\hline \multicolumn{2}{|l|}{ Khonka } & \multicolumn{2}{|c|}{2.03} \\
\hline \multicolumn{2}{|l|}{ Khiva } & \multicolumn{2}{|c|}{1.74} \\
\hline
\end{tabular}

\subsection{4 experimental results}

The mean specific leaf area in $2004(\mathrm{n}=12)$ was $11.3 \mathrm{~m}^{2} \mathrm{~kg}^{-1}$; slightly lower than in 2005 . The leaf area index during the 2004 cropping season varied among the sites, whether measured destructively or with the LAI-2000 (Fig. 4).

The highest leaf area index measured in the Khiva field reached on average $2.1 \mathrm{~m}^{2} \mathrm{~m}^{-2}$ in mid-August. On the Khonka field, leaf area index development was delayed and reached its peak of, on average, $1.75 \mathrm{~m}^{2} \mathrm{~m}^{-2}$ only at the end of September, suggesting some early plant stress. Overall, the field-observed leaf area indices of cotton in farmer's fields were not as high as under optimal, researcher managed conditions in 2005. This might be partly explained by the farmer's practice to cut the main shoot of cotton during boll formation, when the cotton plant has produced at least 15 sympodial branches. Whereas this practice may stimulate maturing, yield enhancement and source-sink relationships, it concurrently prevents further phototropic growth and thus the increase in leaf area index. However, as this was done only in the second half of August, it cannot explain the rather small increase in leaf area index at the beginning of August.

As was the case in 2005 (see Tab. I), aboveground biomass development during early growth linearly followed leaf area index development. The Khiva and Khonka fields showed similar relative increases but with different overall biomass accumulation (Tab. II).

It could not be ascertained whether the decrease of aboveground biomass at Khiva from 8.68 to $7.43 \mathrm{Mg} \mathrm{ha}^{-1}$ between 
a)

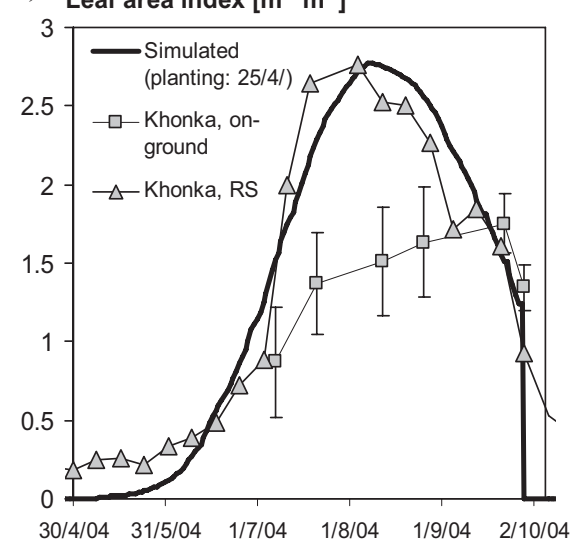

b) Leaf area index $\left[\mathrm{m}^{2} \mathrm{~m}^{-2}\right]$

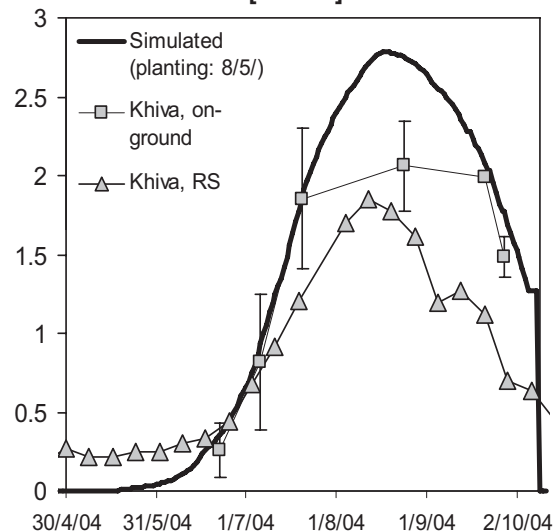

Figure 4. Observed (squares, 'field'; Blenk, 2005), derived from the Normalized Difference Vegetation Index (triangles, 'RS') and simulated (thick line) leaf area index in 2004 of the cotton field in (a) Khonka and (b) Khiva; bars denote the standard deviation.

Table III. CropSyst model settings for the cotton cultivar Khorezm127; $\mathrm{C}=$ calibrated parameters (literature source in parenthesis, if applicable), $\mathrm{D}=$ model default, $\mathrm{O}=$ observed data.

\begin{tabular}{|c|c|c|}
\hline & Value & Source \\
\hline Life cycle and land use & \multicolumn{2}{|c|}{ Annual row crop } \\
\hline Photosynthetic pathway & \multicolumn{2}{|l|}{$\mathrm{C} 3$} \\
\hline Harvested biomass & \multicolumn{2}{|l|}{ Seed $*$} \\
\hline Biomass/transpiration coefficient $\left[\mathrm{kg} \mathrm{m}^{-2} \mathrm{kPa} \mathrm{m}^{-1}\right]$ & 8.1 & $\mathrm{C}$ \\
\hline Radiation use efficiency $\left[\mathrm{g} \mathrm{MJ}^{-1}\right]$ & 2.0 & $\mathrm{C}$ \\
\hline Optimum mean daily temperature for growth & 25 & $\mathrm{C}$ \\
\hline Initial green leaf area index $\left[\mathrm{m}^{2} \mathrm{~m}^{-2}\right]$ & 0.011 & $\mathrm{D}$ \\
\hline Expected maximum LAI & 3 & $\mathrm{O}$ \\
\hline Fraction of maximum LAI at physiological maturity & 0.55 & $\mathrm{O}$ \\
\hline Specific leaf area, SLA $\left[\mathrm{m}^{2} \mathrm{~kg}^{-1}\right]$ & 13.0 & $\mathrm{O}$ \\
\hline Leaf/stem partition coefficient, SLP & 3.0 & $\mathrm{C}$ \\
\hline Leaf duration $\left[{ }^{\circ} \mathrm{C}\right.$ day] & 950 & $\mathrm{O}$ \\
\hline Extinction coefficient for solar radiation & 0.9 & C (Ko et al., 2005) \\
\hline Accumulated growing degree days from & & \\
\hline seeding to emergence $\left[{ }^{\circ} \mathrm{C}\right.$ day $]$ & 110 & $\mathrm{O}$ \\
\hline seeding to peak LAI $\left[{ }^{\circ} \mathrm{C}\right.$ day] & 1200 & $\mathrm{O}$ \\
\hline seeding to flowering $\left[{ }^{\circ} \mathrm{C}\right.$ day $]$ & 1165 & $\mathrm{O}$ \\
\hline seeding to beginning grain filling $\left[{ }^{\circ} \mathrm{C}\right.$ day] & 1180 & $\mathrm{C}$ \\
\hline seeding to maturity $\left[{ }^{\circ} \mathrm{C}\right.$ day] & 1630 & $\mathrm{C}$ \\
\hline Base temperature $\left[{ }^{\circ} \mathrm{C}\right]$ & 8 & $\mathrm{C}$ \\
\hline Cutoff temperature $\left[{ }^{\circ} \mathrm{C}\right]$ & 20 & $\mathrm{C}$ \\
\hline Unstressed harvest index & 0.41 & $\mathrm{O}$ \\
\hline
\end{tabular}

* Assumed to include cotton lint.

25 August to 28 September was significant since only a single bulk sample was taken. However, a loss of aboveground biomass could be due to plant stress and a subsequent cast of immature cotton bolls, a common behaviour of cotton. Final aboveground biomass of the Khonka field was $8.15 \mathrm{Mg} \mathrm{ha}^{-1}$.

\subsection{Model results}

\subsubsection{Model calibration}

Calibrated model parameters are given in Table III. CropSyst calibration started with optimizing the base and cutoff temperature, while constantly updating growing degree days so that simulated phenological stages would always match observations. The base and cutoff temperatures determine the onset and speed of accumulation of growing degree days. Optimal simulation results were gained with a base temperature of $8{ }^{\circ} \mathrm{C}$ and a cutoff temperature of $20{ }^{\circ} \mathrm{C}$. The rather low cutoff value avoided an excessive shortening of phenological stages in response to higher-than-average ambient temperatures, which would strongly decrease the overall time of simulated biomass development and thus under-estimate the real biomass accumulation. Our settings for base and cutoff temperature made the cotton-model insensitive to extraordinarily high maximum temperatures in summer. This is in line with the 2005 field observation and local expert knowledge. It also warrants the scepticism about the 1:1 applicability of the growing degree day concept to cotton (Constable, 1976; Bradow and Davidonis, 2000; Bange and Milroy, 2004).

Base temperature and the optimal temperature for growth influence the value of the air temperature dependent, growthlimiting factor, $\mathrm{T}_{\text {lim }}$. Optimal simulation results were achieved with the optimal temperature for growth equal $25{ }^{\circ} \mathrm{C}$. This value assured that early simulated growth in April and late growth after mid-September was constrained by low air temperatures through $\mathrm{T}_{\mathrm{lim}}$. This phenomenon is common for cotton growth in Khorezm and leads occasionally to late plantings, e.g. when April temperatures are below average. It also reduces, and finally shuts off, late-season biomass accumulation, which is in line with reality. Yet, with $25^{\circ} \mathrm{C}$ as optimal temperature for growth, biomass accumulation was never noticeably restricted by $\mathrm{T}_{\lim }$ in June, July and August. These are the optimum growth months for cotton in Khorezm. Reddy et al. (1991) achieved highest growth rates with cotton in controlled environment chambers at constant day temperatures of $30{ }^{\circ} \mathrm{C}$ and night temperatures of $20^{\circ} \mathrm{C}$, i.e. on average $25^{\circ} \mathrm{C}$ as in our study.

The leaf/stem partition coefficient was optimized together with the radiation use efficiency and the biomass-transpiration coefficient. With a leaf/stem partition coefficient of $3 \mathrm{~m}^{2} \mathrm{~kg}^{-1}$, 
a radiation use efficiency of $2.0 \mathrm{~g} \mathrm{MJ}^{-1}$ and a biomasstranspiration coefficient of $8.1 \mathrm{~kg} \mathrm{~m}^{2} \mathrm{kPa} \mathrm{m}^{-1}$ simulated aboveground biomass approached observed aboveground biomass. Simulated leaf area index followed observed leaf area dynamics and matched observations on 5 August (Fig. 5).

During the hottest growth period in July and August, when vapour pressure deficit reached its maximum, simulated biomass accumulation was governed by transpirationdependent growth as parameterized in equation (3) and not by radiation use efficiency once this was above $1.7 \mathrm{~g} \mathrm{MJ}^{-1}$. Contrarily, radiation use efficiency governed growth in September. With the final settings, the model underestimated aboveground biomass on 11 July by $\sim 1.0 \mathrm{Mg} \mathrm{ha}^{-1}$ (Fig. 5b). Matching simulated and observed aboveground biomass and leaf area index at this date by further increasing the biomass-transpiration coefficient automatically led to a strong overestimation of final aboveground biomass and yield. This would have defeated the primary target of our modelling efforts, which is an exact determination of final aboveground biomass and yield. Thus, we kept the settings as outlined in Table III. Therewith, the root mean square error between simulated and observed leaf area index and aboveground biomass was $0.36 \mathrm{~m}^{2} \mathrm{~m}^{-2}$ and $0.97 \mathrm{Mg} \mathrm{ha}^{-1}$, respectively.

Several studies have shown that overall photosynthesis rate, which is triggered by the biomass-transpiration coefficient and the radiation use efficiency in CropSyst, is higher during early development than later during the main season (Constable and Rawson, 1980; Peng and Krieg, 1991). Apparently, young cotton can increase biomass considerably with only a relatively small leaf area. Furthermore, our studies show that the specific leaf area of young cotton plants is considerably higher than that of older plants. The specific leaf area also determines leaf area index (Eq. (6)). This imposes some restrictions of modelling cotton with CropSyst. To cope with the rapid increase in biomass of young cotton, the biomass-transpiration coefficient, radiation use efficiency and specific leaf area would have to be dynamically changed during plant growth, a feature which is not yet available in CropSyst.

Data presented by Milroy and Bange (2003) confirm that radiation use efficiency of cotton (Sicala $V$-2i) varies greatly with age, between the canopy layers, and also in response to varying leaf-N-concentration. Their measurements resulted in radiation use efficiency values ranging from as low as 0.81 to as high as $3.1 \mathrm{~g} \mathrm{MJ}^{-1}$. Other studies report radiation use efficiencies of $2.0 \mathrm{~g} \mathrm{MJ}^{-1}$ (Paymaster $2326 \mathrm{BG} / R R$ grown in Texas; Ko et al., 2005), $2.55 \mathrm{~g} \mathrm{MJ}^{-1}$ (Acala SJ-2 grown in California; Howell and Musick, 1985, cited in Rosenthal and Gerik, 1991) and 1.29-1.66 $\mathrm{g} \mathrm{MJ}^{-1}$ (Acala SJ-2, Deltapine 50 and Tamcot CD3H grown in Texas; Rosenthal and Gerik, 1991). The latter is a bit lower than the radiation use efficiency of Khorezm-127.

Values of the biomass-transpiration coefficient for cotton could not be found in the literature. The concept for this coefficient in CropSyst goes back to the work of Tanner and Sinclair (1983), who developed various equations for biomass production and transpiration. See also Kremer et al. (2008), for a more recent discussion of this approach. With $8.1 \mathrm{~kg} \mathrm{~m}^{-2} \mathrm{kPa} \mathrm{m}^{-1}$ our value exceeds default values given in the CropSyst manual. This is attributed to the arid climate of the study region with extremely high daily mean vapour pressure deficits leading to a decrease in biomass accumulation (Eq. (3)). A high biomass-transpiration coefficient is necessary for counter-balancing this trend, indicating that the growth concept expressed in equation (3) needs revision for arid climates.

\subsubsection{Model evaluation}

An independent data set of biomass and leaf area index development of cotton grown under stress-free conditions in Khorezm was unavailable. Completely stress-free growth conditions might be neither economically desirable nor feasible from an irrigation-engineering perspective. We compared simulated leaf area index and biomass dynamics with measured values in 2004 obtained from two fields in Khiva and Khonka, which were managed by farmers and where near optimum growth and leaf area index development were observed.

\section{Aboveground biomass}

Simulations of early cotton aboveground biomass development until mid-August of the Khonka and Khiva field matched the field data reasonably well (Tab. II). Final aboveground biomass, however, was overestimated by the model. The drop in aboveground biomass of the cotton in the Khiva field around late August was not properly captured by the model. As it was set for optimal conditions, CropSyst could not properly simulate the late season plant stress that impaired growth on these sites. The RMSE between simulated and observed aboveground biomass was high (1.74 to $2.03 \mathrm{Mg} \mathrm{ha}^{-1}$ ). As these are based on only three or four repetitions in aboveground biomass determination, these numbers should be interpreted with care.

\section{Leaf area index}

Simulations almost perfectly reproduced early fieldobserved leaf area index in Khiva (Fig. 4). In Khonka simulated leaf area index development tended to be ahead of real development by some days, as was observed also for the 2005-data during calibration. This gap increased with time. The model did not reproduce the slow-down in leaf area index development after 20 July on either site. Due to these inconsistencies, the RMSE between simulated and observed leaf area index in Khonka with $0.82 \mathrm{~m}^{2} \mathrm{~m}^{-2}$ was rather high, while in Khiva it was comparably low $\left(0.47 \mathrm{~m}^{2} \mathrm{~m}^{-2}\right)$.

The highest NDVI-derived leaf area index came from the MODIS pixel completely covering one part of the cotton field in Khonka (Fig. 4). Here, modelled and remotely sensed leaf area index matched well, with a RMSE of $0.24 \mathrm{~m}^{2} \mathrm{~m}^{-2}$ (period: planting till maturity). In the Khiva field, on-site measurements yielded higher leaf area indices than estimated with the MODIS NDVI of the only corresponding pixel (compare Fig. 4). This pixel covered also parts of the neighbouring 
a)

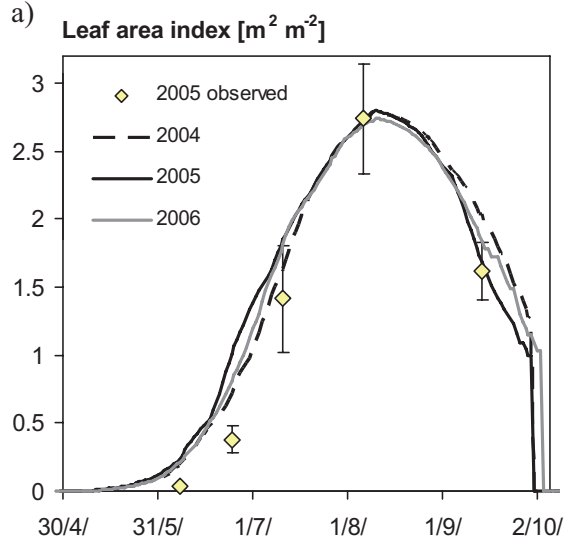

b)

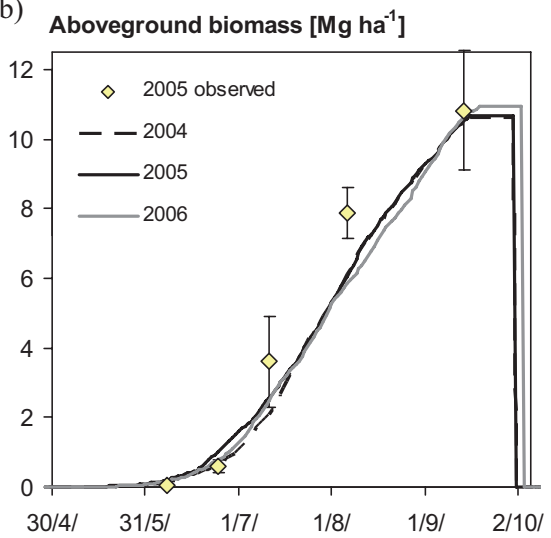

Figure 5. Observed (points) and simulated (lines) (a) leaf area index and (b) aboveground biomass in 2005, as well as simulated leaf area index and aboveground biomass in 2004 and 2006; bars denote the standard deviation.

fields, which were mapped as bare soil during the 2004 season. This may explain the lower NDVI values and the higher RMSE between simulated and NDVI-derived leaf area index of $0.68 \mathrm{~m}^{2} \mathrm{~m}^{-2}$. In contrast, the "optimum" pixel in Khonka was identified as "full pixel" and was therefore more suitable to evaluate the model. Clearly, more research is necessary to close the gap between NDVI-derived leaf area index and destructive or LiCor-2000 leaf area index measurements in the field. Research should focus on reducing the rather high uncertainty of the NDVI-leaf area index relationship at leaf area indices $>1.5 \mathrm{~m}^{2} \mathrm{~m}^{-2}$. Figure 2 indicates that for a leaf area index of $1.95 \mathrm{~m}^{2} \mathrm{~m}^{-2}$, the $95 \%$ confidence interval of the non-linear regression analysis allows the NDVI to range from as low as 0.61 to as high as 0.75 . The rather high NDVI-derived leaf area index of around $0.25 \mathrm{~m}^{2} \mathrm{~m}^{-2}$ in early May is an artefact of the optimized parameter $\mathrm{NDVI}_{\mathrm{bs}}$ (equal 0) in equation (2) rather than reflecting real behaviour.

\section{Model stability}

Comparing results of simulations carried out for the years 2004 and 2006 (Fig. 5) showed that simulated aboveground biomass and leaf area index development under optimal conditions was stable throughout the years. Total simulated aboveground biomass at maturity was $10.63 \mathrm{Mg} \mathrm{ha}^{-1}$ in 2004 and $10.92 \mathrm{Mg} \mathrm{ha}^{-1}$ in 2006. The maximum leaf area index ranged between 2.78 and $2.79 \mathrm{~m}^{2} \mathrm{~m}^{-2}$ in these years. Relatively stable aboveground biomass and yield are to be expected in a region such as Khorezm that is characterized by a stable, arid climate with hot, dry and clear-sky summers. Also, key phenological stages varied little. Peak flowering date $\left(1165^{\circ} \mathrm{C}\right.$-days $)$ according to the simulation was reached between 8 and $9 \mathrm{Au}-$ gust and maturity $\left(1630{ }^{\circ} \mathrm{C}\right.$-days) between 16 and 19 September in all three years.

\section{GENERAL DISCUSSION}

Our study is the first that provides a calibration of CropSyst for cotton. The 2005 calibration results are encouraging given the rather low RMSE between simulated and observed leaf area index and aboveground biomass. However, we could not correct the tendency of the model to underestimate early aboveground biomass, which we assume is caused by the radiation use efficiency as well as the specific leaf area of cotton which are not fixed (as assumed by CropSyst) but gradually decrease with plant age. Nevertheless, the deviation between observed and simulated early aboveground biomass is tolerable for the purpose of our studies, where irrigation, $\mathrm{N}$-fertilization and soil salinity management and its effect on cotton yield are of primary importance.

Evaluation of the CropSyst cotton model with an independent data set on optimal cotton growth in Khorezm, Uzbekistan left some issues unresolved. Optimal cotton growth is the exception rather than the rule in Khorezm and hence this type of data is rarely generated by cotton breeders and agronomists. The observations in 2004 and other experiments have shown that cotton is often exposed to water stress, high soil salinity or inadequate fertilization, poor seed quality and inadequate crop management. Thus, the 2004 data set only partly qualified as an independent data set for evaluating simulated optimal cotton growth. Still, simulated early leaf area index and biomass development did reproduce field observation reasonably well, evidencing that CropSyst was well parameterized to describe cotton growth during this period. Furthermore, there was evidence from single measurements in 2004 that the leaf area index can reach simulated maximum values and local experts confirmed these findings.

The excellent fit of early NDVI-derived leaf area index and observations at the Khonka site is encouraging for the use of NDVI-derived leaf area index data for model evaluation. The high frequency of observations and the spatially integrative character of this approach make NDVI attractive for modelling purposes. Further analyses should clarify the inconsistencies between field-based determination of leaf area index and remotely-sensed values. Furthermore, the full potential of remote sensing can only be assessed when plant stress factors are properly dealt with in the simulation model, as plant stress appeared to have occurred. These factors should help closing the gap between simulation results and field observations. 
Remote sensing techniques were successfully applied by $\mathrm{Li}$ et al. (2001) to assess crop growth characteristics in cotton and related attributes (soil, elevation, etc.) and by Zhao et al. (2004) for assessing the response of cotton canopy reflectance to different $\mathrm{N}$ application rates. However, few attempts have been made so far to combine remote sensing or GIS with fullfledged crop soil simulation models such as CropSyst (e.g. Moriondo, 2007; see Hartkamp et al., 1999, for a review on this issue).

Late maturity of cotton was simulated for the year 2004 in response to late (re-)planting on the Khiva field. Such responses are of special importance to farmers in Khorezm. Farmers obtain their highest prices for cotton delivered before a certain deadline in September. Mostly first-pick cotton of comparatively high quality is delivered at this time. In this respect, aggregating cotton picks to only a single harvest event coinciding with the period of first cotton picking is a shortcoming of the model in its current form. The amount of cotton actually harvested at this time can only be derived empirically.

A range of other cotton-specific features could not be considered in the crop growth routine of the CropSyst model, such as boll numbers, lint quality, or the potential use defoliating agents. Other models such as Cotton2k (Marani, 2006), the GRAMI model (Maas, 1992), or OZCOT (Hearn, 1994) as part of APSIM (Keating et al., 2003) provide some of these features. We did not use either of the first two or any other cotton-only model, because within the framework of our study we intended to simulate also other crops than cotton as well as the effect of crop rotation. APSIM would have qualified for our studies, yet was not considered further because of the involved licence costs for APSIM, which our stakeholders would be unable to afford. We opted for CropSyst as it is freely available and allows integration of several crops for cropping system optimization. Moreover, it has a generic crop growth routine that allows modelling of additional, undocumented crops, such as Indigo (Indigofera tinctoria). It can handle constraints such as salinity (Ferrer-Alegre and Stockle, 1999) and shallow groundwater which are important in the study region, and finally, it provides a GIS-interface for integrated spatial analysis of crop growth and agro-ecological consequences (e.g. N-leaching and salinization).

\section{CONCLUSION}

CropSyst was successfully calibrated to simulate optimal cotton growth of Khorezm-127, the predominant cotton variety in Khorezm. The indeterminate growth characteristics of cotton, i.e. the continuous maturing of single cotton bolls, in Khorezm requiring up to three cotton picks, could not be reproduced in detail by the model. A single maturity date is assumed to be reached after a certain number of growing degree days. In view of the project goal to develop a decision support system for a spatially explicit agronomic optimization of cropping cycles, this simplification is acceptable and compensated for by various other advantages of CropSyst.

According to own observations and local experts, cotton in Khorezm rarely grows stress-free and data sets satisfying the requirement of optimal growth need to be especially produced (as was the case in 2005). Further evaluation of the CropSyst cotton routine with an independent data set was constrained by the fact that the fields managed by farmers generally do not meet optimal conditions. Discrepancies between observations and simulation results are readily explained by plant stress that decreased leaf area index and aboveground biomass of cotton on the two evaluation sites. Thus the evaluation data set did not meet optimal growth. This is a common problem in crop-modelling as available data sets rarely fulfil modelling requirements.

Leaf area index determined directly in the field and the NDVI-derived leaf area index deviated notably and further research is necessary to establish a firm empirical relationship between the two parameters. Nevertheless, the availability of NDVI data in high temporal and acceptable spatial resolution opens possibilities for a precise, in-expensive and resourceefficient way of model calibration and evaluation. This approach was successfully applied by Falkenberg et al. (2007), who used remote sensing to identify and distinguish biotic and abiotic stress in cotton, a method that might be ready to be tested on cotton in Khorezm.

Acknowledgements: This study was funded by the German Ministry for Education and Research (BMBF; project number 0339970A).

\section{REFERENCES}

Allen R.G., Pereira L.S., Raes D., Smith M. (1998) Crop evapotranspiration - Guidelines for computing crop water requirements - FAO Irrigation and drainage paper 56, Food and Agriculture Organization of the United Nations, Rome.

Bange M.P., Milroy S.P. (2004) Impact of short-term exposure to cold night temperatures on early development of cotton (Gossypium hirsutum L.), Aust. J. Agr. Res. 55, 655-664.

Baret F., Guyot. G. (1991) Potentials and limits of vegetation indices for leaf area index and APAR assessment, Remote Sens. Environ. 35, $161-173$.

Bechini L., Bocchi S., Maggiore T., Confalonieri R. (2006) Parameterization of a crop growth and development simulation model at sub-model components level. An example for winter wheat (Triticum aestivum L.), Environ. Modell. Softw. 21, $1042-1054$.

Blenk S. (2005) Derivation of the leaf area index for cotton and rice based on in-situ measurements and MODIS remote sensing data, University of Würzburg, Unpublished Master Thesis (in German), $154 \mathrm{p}$.

Bradow J.M., Davidonis G.H. (2000) Review: Quantitation of fiber quality and the cotton production-processing interface: A physiologist's perspective, J. Cotton Sci. 4, 34-64.

Confalonieri R., Bechini L. (2004) A preliminary evaluation of the simulation model CropSyst for alfalfa, Eur. J. Agron. 21, 223-237.

Confalonieri R., Bocchi S. (2005) Evaluation of CropSyst for simulating the yield of flooded rice in Italy, Eur. J. Agron. 23, 315-326.

Confalonieri R., Gusberti D., Bocchi B., Acutis M. (2006) The CropSyst model to simulate the $\mathrm{N}$ balance of rice for alternative management, Agron. Sustain. Dev. 26, 241-249.

Conrad C. (2006) Remote sensing based modeling and hydrological measurements for the assessment of agricultural water use in the 
Khorezm region (Uzbekistan), University of Wuerzburg, Ph.D. Thesis (in German), 205 p.

Constable G.A. (1976) Temperature effects on the early field development of cotton, Aust. J. Exp. Agr. Anim. Husb. 16, 905-910.

Constable G.A., Rawson H.M. (1980) Effect of leaf position, expansion and age on photosynthesis, transpiration and water use efficiency of cotton, Aust. J. Plant Physiol. 7, 89-100.

Falkenberg N.R., Piccinni G., Cothren J.T., Leskovar D.I., Rush C.M (2007) Remote sensing of biotic and abiotic stress for irrigation management of cotton, Agr. Water Manage. 87, 23-31.

FAOSTAT (2006) Trade/Crops \& livestock primary \& processed; Production/Crops Primary; last accessed Nov. 2006.

Ferrer-Alegre F., Stockle C.O. (1999) A model for assessing crop response to salinity, Irrigation Sci. 19, 15-23.

Hartkamp A.D., White J.W., Hoogenboom G. (1999) Interfacing geographic information systems with agronomic modeling: a review, Agron. J. 91, 761-772.

Hearn A.B. (1994) OZCOT: a simulation model for cotton crop management, Agr. Syst. 44, 257-299.

Huete A.R., Didan K., Miura T., Rodriguez E.P., Gao X., Ferreira L.G. (2002) Overview of the radiometric and biophysical performance of the MODIS vegetation indices, Remote Sens. Environ. 83, 195213.

Ismoilov U.E. (2004) The scientific basis of increasing the soil fertility, (In Russian), Nukus, Bilim, 186 p.

Li H., Lascano R.J., Barnes E.M., Brooker J., Wilson L.T., Bronson K.F., Segarra E. (2001) Multispectral reflectance of cotton related to plant growth soil water and texture, and site elevation, Agron. J. 93, 1327-1337.

Keating B.A., Carberry P.S., Hammer G.L., Probert M.E., Robertson M.J., Holzworth D., Huth N.I., Hargreaves J.N.G., Meinke H., Hochman Z., McLean G., Verburg K., Snow V., Dimes J.P., Silburn M., Wang E., Brown S., Bristow K.L., Asseng S., Chapman S., McCown R.L., Freebairn D.M., Smith C.J. (2003) An overview of APSIM, a model designed for farming systems simulation, Eur. J. Agron. 18, 267-288.

Ko J., Maas S.J., Lascano R.J., Wanjura D. (2005) Modification of the GRAMI model for cotton, Agron. J. 97, 1374-1379.

Kremer C., Stockle C.O., Kemanian A.R., Howell T. (2008) A reference canopy transpiration and photosynthesis model for the evaluation of simple models of crop productivity, accepted for publication by Agronomy Journal.

Maas S.J. (1992) GRAMI: A crop growth model that can use remotely sensed information, ARS-91 USDA, Washington, DC.

Marani A. (2006) Cotton2K Model version 4.0., Internet Publikation: http://departments.agri.huji.ac.il/plantscience/cotton/Cotton2KModelDoc.htm.
Martius C., Lamers J.P.A., Wehrheim P., Schoeller-Schletter A., Eshchanov R., Tupitsa A., Khamzina A., Akramkhanov A., Vlek P.L.G. (2004) Developing sustainable land and water management for the Aral Sea Basin through an interdisciplinary research. in: Seng V., Craswell E., Fukai S. (Eds.), Water in agriculture, ACIAR Proceedings No. 116, Canberra, pp. 45-60.

Milroy S.P., Bange M.P. (2003) Nitrogen and light response of cotton photosynthesis and implications for crop growth, Crop Sci. 43, 904-913.

Moriondo M., Maselli F., Bindi M. (2007) A simple model of regional wheat yield based on NDVI data, Eur. J. Agron. 26, 266-274.

Pannkuk C.D., Stockle C.O., Papendiek R.I. (1998) Evaluating CropSyst simulations of wheat management in a wheat-fallow region of the US Pacific Northwest, Agr. Syst. 57, 121-134.

Peng S., Krieg D.R. (1991) Single leaf and canopy photosynthesis response to plant age in cotton. Agron. J. 83, 704-708.

Reddy V.R., Acock B., Baker D.N., Acock M. (1989) Seasonal leaf arealeaf weight relationships in the cotton canopy, Agron. J. 81, 1-4.

Reddy V.R., Baker D.N., Hodges H.F. (1991) Temperature effects on cotton canopy growth, photosynthesis, and respiration, Agron. J. 83, 699-704.

Rosenthal W.D., Gerik T.J. (1991) Radiation use efficiency among cotton cultivars, Agron. J. 83, 655-658.

Scheer C., Wassmann R., Kienzler K., Ibragimov N., Eshanov R. (2008) Nitrous oxide emissions from fertilized, irrigated cotton (Gossypium hirsutum L.) in the Aral Sea Basin, Uzbekistan: Influence of nitrogen applications and irrigation practices, Soil Biol. Biochem. 40, 290-301.

Sommer R., Wall P.C., Govaerts B. (2007) Model-based assessment of maize cropping under conventional and conservation agriculture in highland Mexico, Soil Till. Res. 94, 83-100.

Stockle C.O., Donatelli M., Nelson R. (2003) CropSyst, a cropping systems simulation model, Eur. J. Agron. 18, 289-307.

Tanner C.B., Sinclair T.R. (1983) Efficient water use crop production: Research or Re-search? in: Taylor H.M., Jordan W.R., Sinclair T.R. (Eds.), Limitations to Efficient Water Use in Crop Production, pp. 1-27, ASA-CSSA-SSSA, Madison, 538 p.

Vermote E.F., El Saleous N.Z., Justice C.O. (2002) Atmospheric correction of MODIS data in the visible to middle infrared: first results, Remote Sens. Environ. 83, 97-111.

Zhao D., Li J., Qi J. (2004) Hyperspectral characteristic analysis of a developing cotton canopy under different nitrogen treatments, Agronomie 24, 463-471. 